\title{
Adaptation of Propionibacterium freudenreichii to long-term survival under gradual nutritional shortage
}

\author{
Flavia Figueira Aburjaile ${ }^{1,2,3}$, Marine Rohmer ${ }^{4}$, Hugues Parrinello ${ }^{4}$, Marie-Bernadette Maillard ${ }^{2,3}$, Eric Beaucher ${ }^{2,3}$, \\ Gwénaële Henry ${ }^{2,3}$, Aurélie Nicolas ${ }^{2,3}$, Marie-Noëlle Madec ${ }^{2,3}$, Anne Thierry ${ }^{2,3}$, Sandrine Parayre ${ }^{2,3}$, \\ Stéphanie-Marie Deutsch ${ }^{2,3}$, Muriel Cocaign-Bousquet ${ }^{5}$, Anderson Miyoshi ${ }^{1}$, Vasco Azevedo ${ }^{1}$, Yves Le Loir ${ }^{2,3+}$ \\ and Hélène Falentin ${ }^{2,3^{*}+}$
}

\begin{abstract}
Background: Propionibacterium freudenreichii is an Actinobacterium widely used in the dairy industry as a ripening culture for Swiss-type cheeses, for vitamin B12 production and some strains display probiotic properties. It is reportedly a hardy bacterium, able to survive the cheese-making process and digestive stresses.

Results: During this study, P. freudenreichii CIRM-BIA 138 (alias ITG P9), which has a generation time of five hours in Yeast Extract Lactate medium at $30{ }^{\circ} \mathrm{C}$ under microaerophilic conditions, was incubated for 11 days (9 days after entry into stationary phase) in a culture medium, without any adjunct during the incubation. The carbon and free amino acids sources available in the medium, and the organic acids produced by the strain, were monitored throughout growth and survival. Although lactate (the preferred carbon source for $P$. freudenreichii) was exhausted three days after inoculation, the strain sustained a high population level of $9.3 \log _{10} \mathrm{CFU} / \mathrm{mL}$. Its physiological adaptation was investigated by RNA-seq analysis and revealed a complete disruption of metabolism at the entry into stationary phase as compared to exponential phase.

Conclusions: $P$. freudenreichii adapts its metabolism during entry into stationary phase by down-regulating oxidative phosphorylation, glycolysis, and the Wood-Werkman cycle by exploiting new nitrogen (glutamate, glycine, alanine) sources, by down-regulating the transcription, translation and secretion of protein. Utilization of polyphosphates was suggested.
\end{abstract}

Keywords: Propionibacterium freudenreichii, Long-term survival, Stationary phase, RNA-seq, Adaptation

\section{Background}

Propionibacterium freudenreichii is an Actinobacterium widely used in the dairy industry and responsible for aroma development and opening (eyes) in Swiss-type cheeses. Some strains are also used as probiotics because they produce bifidogenic compounds [1], they are resistant to digestive stress [2] and they may be endowed with anti-inflammatory capabilities and could be used to

\footnotetext{
* Correspondence: helene.falentin@rennes.inra.fr

${ }^{\dagger}$ Equal contributors

'INRA, UMR 1253, Science et Technologie du Lait et de I' CFuf, 35000 Rennes, France

${ }^{3}$ AGROCAMPUS OUEST, UMR1253, UMR Science et Technologie du Lait et de I'Euf, 35000 Rennes, France

Full list of author information is available at the end of the article
}

prevent inflammatory bowel diseases [3] [4]. P. freudenreichii core metabolism leads to propionic acid as the main end-product [5].

The genetic bases for hardiness have already been well-documented. $P$. freudenreichii can produce ATP and $\mathrm{NAD}(\mathrm{P}) \mathrm{H}$ via fermentation utilizing an unique metabolic pathway (the Wood-Werkman cycle), leading to propionic acid. Under anaerobiosis, $P$. freudenreichii can also use electron acceptors other than $\mathrm{O}_{2}$ (such as humic acid or nitrate) to produce ATP during anaerobic respiration [5, 6]. Several genes involved in polyphosphate and pyrophosphate utilization are found in the genome of CIRM-BIA1, the type strain for P. freudenreichii, suggesting a storage of energy in these forms [7]. 
An inorganic pyrophosphatase-coding gene was found to be overexpressed in the cold in 6 strains of $P$. freudenreichii [8]. P. freudenreichii can stay alive and metabolically active for long periods even under stressful conditions like gastro-intestinal tract environment or in cold condition. When placed at stationary phase in the intestinal tract (colon) of a piglet, CIRM-BIA1 was able to ferment some atypical carbon sources present in the gut (gluconate and propanediol), enabling its survival under these harsh conditions. Both of these catabolic pathways were reconstructed in silico from the genomic data and were found to be fully expressed in the colon of piglets [9]. Another transcriptomic study on the adaptation of $P$. freudenreichii strains to the cold (with lactate fully available) showed that strains slowed down their cellular metabolism, displayed cold stress responses, and rerouted their carbon metabolism toward trehalose and glycogen synthesis [8]. In addition, proteomic studies on different $P$. freudenreichii strains have highlighted the role of chaperones during exposure to acids, bile salts or $\mathrm{NaCl}$ [10-12]. The genomic analysis of $P$. freudenreichii strains thus revealed the duplication of several chaperone genes.

In a previous study [13], we carried out the phenotypic characterization of $P$. freudenreichii over an 11-day period without the addition of nutrients, and revealed different phases of growth, membrane permeabilization and entry into dormancy and a viable but non-culturable state to ensure Long-Term Survival (LTS). How P. freudenreichii prepares the LTS phase remains unknown and no data are currently available on the metabolism of $P$. freudenreichii in stationary phase in the event of a gradual nutritional shortage.

The objective of the present study was therefore to identify the pathways used by $P$. freudenreichii to cope with starvation and enter the LTS phase. The strategy adopted here combined the quantification of sugars, acids and free amino acids in the supernatant of an 11day culture without the addition of nutrients, and an RNA-seq analysis of bacterial cells sampled at three different time points during $P$. freudenreichii culture. The studies were performed on CIRM-BIA138 strain because it was the strain with the highest survival rate in stationary phase, according to a screening of 23 strains [13]. This work was designed to compare both biochemical quantifications (acids, amino-acids and sugars) and transcriptomic data between the exponential and stationary phases in order to gain an in-depth view of $P$. freudenreichii adaptation to LTS.

\section{Results and discussion}

The objective of the study was to identify the metabolic pathways used by $P$. freudenreichii to cope with starvation and 'prepare' entry into the LTS phase.

\section{Enumeration, DO, pH}

The results of bacterial enumerations and $\mathrm{pH}$ measurements (Fig. 1a) confirmed that CIRM-BIA 138 survived well (around $8 \log _{10} \mathrm{CFU} / \mathrm{mL}$ ) during 11 days, even under conditions of nutritional shortage, as it had been observed during a previous study [13]. When inoculated at $7 \log _{10} \mathrm{CFU} / \mathrm{mL}$, the $P$. freudenreichii culture entered the exponential growth phase to reach a maximum population of $9.3 \log _{10} \mathrm{CFU} / \mathrm{mL} 3 \mathrm{~d}$ post-inoculation, corresponding to entry into the stationary phase. The $\mathrm{pH}$ was very slightly affected by growth since the most acidic point was 6.7 compared to 7 at inoculation time. At entry into stationary phase, a slight decline in the

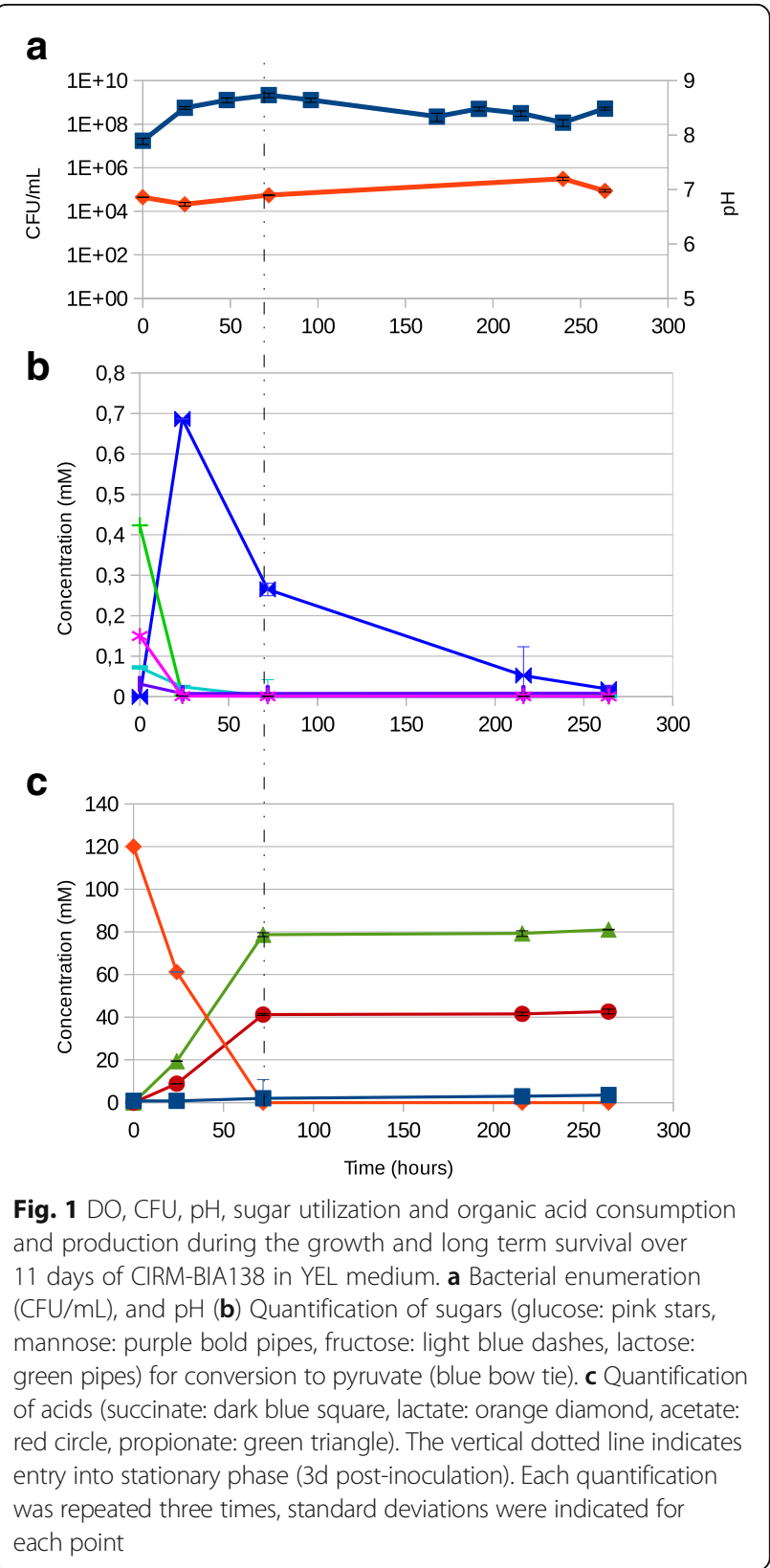


population was observed until it stabilized at around 8.5 $\log _{10} \mathrm{CFU} / \mathrm{mL}$ as from $9 \mathrm{~d}$ post-inoculation (Fig. 1a).

\section{Carbon source utilization, organic acid utilization and production}

P. freudenreichii CIRM-BIA138 can degrade glucose, glycerol, mannose, galactose, inositol, erythritol, adonitol, esculine, lactose, xylitol, gluconate, D-fructose and L-arabinose [14]. In this study, CIRM-BIA138 was cultivated in Yeast Extract Lactate, a growth medium containing $120 \mathrm{mM}$ lactate. Small quantities of several other carbon sources were also identified: $0.42(+/-2 \mathrm{E}-4) \mathrm{mM}$ lactose, $0.15(+/-2 \mathrm{E}-4) \mathrm{mM}$ glucose, $0.07(+/-3 \mathrm{E}-5) \mathrm{mM}$ fructose, $0.03(+/-5 \mathrm{E}-5)$ $\mathrm{mM}$ mannose. Inositol and arabinose were not detected and probably below the detection limit of $0.5 \mathrm{mM}$. P. freudenreichii CIRM-BIA138 used lactose, glucose, mannose and fructose at the beginning of growth until they were completely exhausted at $1 \mathrm{~d}$ post-inoculation (Fig. 1b). These degradation capacities are in line with those previously described for this strain [15]. The degradation of these sugars was concomitant with the release of pyruvate into the medium, this being one of their intermediary metabolites. From 1d post-inoculation onwards, pyruvate was consumed by the strain. Levels of other compounds such as propionate, acetate and succinate rose gradually in the medium over time during growth, to reach a plateau at $3 \mathrm{~d}$ post-inoculation (Fig. 1C). The stoichiometry of the conversion was $3 \mathrm{~mol}$ of lactate into $1 \mathrm{~mol}$ of acetate and $2 \mathrm{~mol}$ of propionate, and is in line with those described previously [14]. Lactate levels decreased as early as the onset of growth because of its consumption by $P$. freudenreichii. Lactate was exhausted $3 \mathrm{~d}$ post-inoculation and pyruvate $11 \mathrm{~d}$ post-inoculation. Among all the carbon sources quantified during this experiment, pyruvate was the only carbon source detectable in the medium when $P$. freudenreichii entered the stationary phase.

\section{Overview of differentially expressed genes between exponential and stationary phases}

After filtration to eliminate reads of poor quality, sequencing generated 100,450,770 reads (FastQC results), which included 13,502,207 non-aligned reads and $37,018,311$ reads aligned on coding sequences. The remaining reads corresponded to those mapping on two different sequences $(1,147,269$ ambiguous reads according an htseq-count with a union parameter), on tRNA, rRNA, or non coding RNA (small RNA, non-sense RNA, 5' and 3 ' UTR). Only reads mapping on coding sequences were further analysed. Overall, 912 genes were found to be differentially expressed (adjusted pvalue $<0.05$ ) between $1 \mathrm{~d}$ (exponential phase) and 3d post- inoculation (start of stationary phase) (458 genes induced (Additional file 1: Table S1), 454 genes repressed (Additional file 2: Table S2). Differentially expressed genes (adjusted pvalues $<0.05$, pvalues available in Additional files 1: Table S1, Additional files 2: S2 and Additional files 3: S3) represented $40 \%$ of the protein-coding genes in the CIRM-BIA138 genome. The genes most affected by entry into stationary phase was those implicated in carbohydrate metabolism with 26 genes of this functional category being induced and 41 repressed. Translation was the second most affected category, with two genes induced and 56 repressed. Transport/binding was the third most affected category, with 28 genes induced and 19 repressed. Transcription was the fourth most affected category, with 29 genes induced and 17 repressed. Membrane bioenergetics was the fifth most affected category, with nine genes induced and 36 repressed. Amino acid metabolism category was also affected, with 11 genes induced and 32 repressed. Lastly, the metabolism of coenzyme and prosthetic groups was also affected, with 11 genes induced and 29 repressed (Fig. 2). Most induction and repression observed from RNAseq analysis were confirmed by RT-qPCR analysis ( $p$ value $<0.05$, Additional file 3: Table S3). To validate RNAseq results, we performed RT-qPCR and we included the $9 \mathrm{~d}$ post-inoculation sample. In most cases, the tendency (induction versus repression) seen at $3 \mathrm{~d}$ post inoculation was confirmed at $9 \mathrm{~d}$. A massive number of differentially expressed genes (63 repressed and 177 induced) were annotated as having an "unknown function". 39\% of induced genes at stationary phase were of unknown function. The genome of CIRM-BIA 138 contains $27 \%$ of genes encoding protein of unknown function (annotated genome available at http:// www.ebi.ac.uk/ena/data/view/PRJEB6433). So, results suggested that genes expressed at the entry into stationary phase are enriched in genes without function, thus reflecting our lack of knowledge on bacterial stationary phase metabolism. All induction and repression discussed below are statistically significant at adjusted pvalue $<0.05$ for RNAseq and at pvalue $<0.05$ for RT-qPCR.

\section{Slowdown of the metabolism leading to dormancy}

RNA extraction and quantification throughout growth and survival showed that RNA levels gradually declined. The total/depleted RNA quantities corresponding to $2 \mathrm{~mL}$ of culture were $60 \mu \mathrm{g} / 290 \mathrm{ng}$ at $1 \mathrm{~d}$ postinoculation (exponential growth phase) for $15 \log _{10}$ CFU, $22 \mu \mathrm{g} / 225 \mathrm{ng}$ at $3 \mathrm{~d}$ post-inoculation (entry into stationary phase) $19 \log _{10}$ CFU and $15 \mu \mathrm{g} / 90 \mathrm{ng}$ at $11 \mathrm{~d}$ post-inoculation $18 \log _{10} \mathrm{CFU}$. The translation machinery was also reduced at $3 \mathrm{~d}$ post-inoculation. Indeed, expression of the translation initiation factor IF-3, and the elongation factors $\mathrm{Tu}$ and $\mathrm{G}$ encoded by genes infC, tuf, 


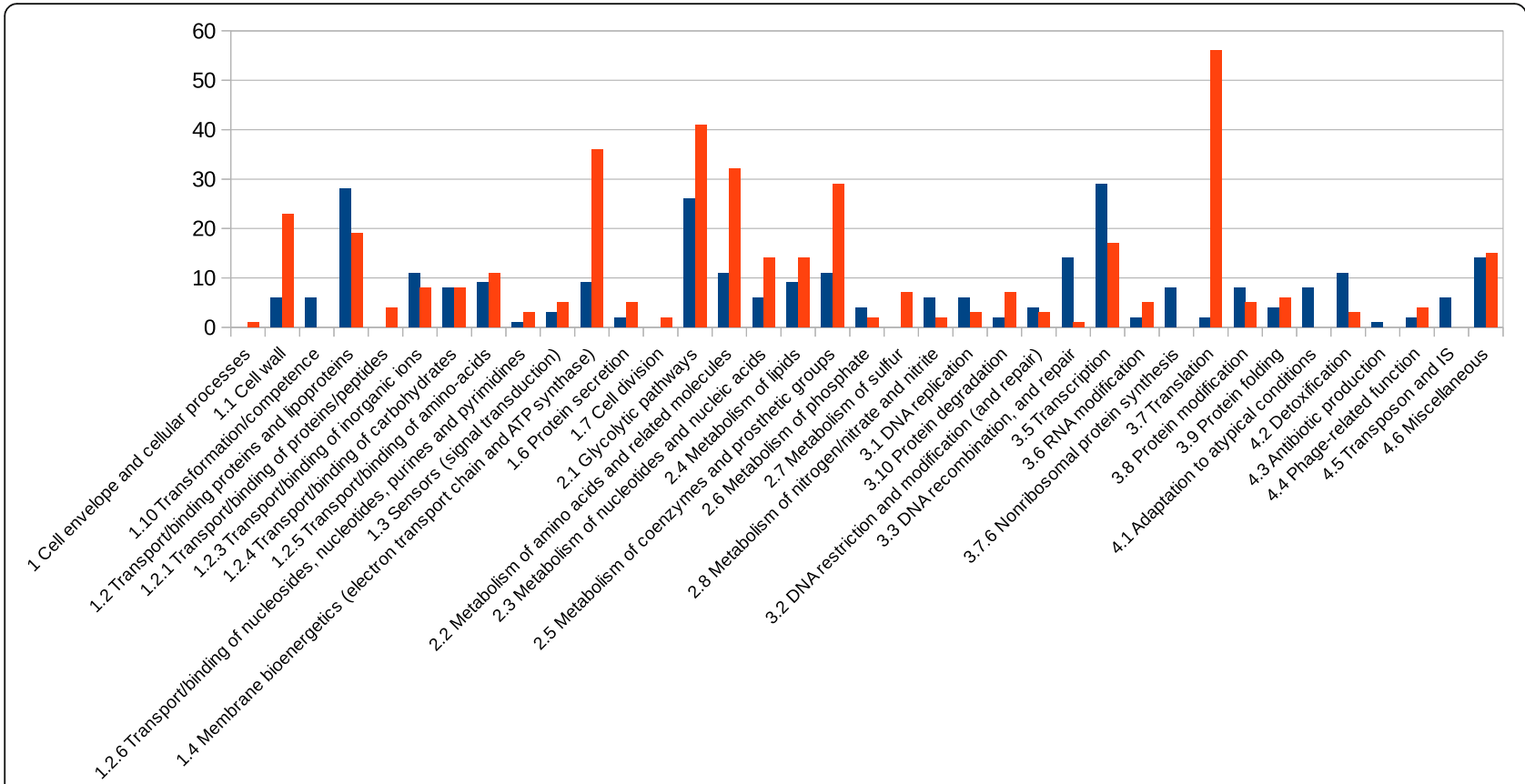

Fig. 2 Number of induced and repressed genes in the stationary phase (3d post-inoculation) compared to the exponential phase (1d postinoculation), classified by metabolic function. In blue and orange: induced and repressed genes, respectively. Differential comparison of groups (each containing three repetitions) were performed gene by gene using a modified $t$-test. Genes were declared as being differentially expressed (DE) with a $P$ value adjusted $\leq 0.05$

fusA, were 2, 1.8 and 3-fold repressed, respectively. The expression of ribosomal proteins was repressed from 1.5 to 16 fold (see Additional file 2: Table S2, for repression fold and pvalue of each gene). The non coding RNA named 'pseudoknot of the domain G(G12) of $23 \mathrm{~S}$ ribosomal RNA' was also repressed with a fold change of 3.7 at the entry into stationary phase (Additional file 2: Table S2). Taken together, these repressions reflected a slowdown of the cellular machinery in line with the process of dormancy recently described [13]. This slowdown can be explained by the scarcity of carbon sources when $P$. freudenreichii enters the stationary phase at $3 \mathrm{~d}$ post-inoculation. The main glycolytic pathways producing reducing equivalents were repressed during this phase. In YEL medium, glycolysis, the pentose phosphate pathway and the Wood-Werkman cycle (fermentation) are three ways for $P$. freudenreichii to produce NADH and NADPH reducing equivalents. ATP and precursor metabolites are required for the biosynthesis of essential compounds (amino acids, purine, pyrimidine, glycerol 3 phosphate, fatty acids, $\mathrm{N}$-acetyl glucosamine, vitamins). Here, under the conditions we applied, glucose was exhausted at $3 \mathrm{~d}$ post-inoculation, and the genes involved in glycolysis were repressed. Some of them were particularly strongly down-regulated, such as $\mathrm{sglT}$, the glucose transporter with a fold change of 4 , and $p f k A, p f p, f b a 1$ and eno2 with fold changes of 2.2, 3.1, 1.9 and 3.4, respectively. The repression of $\operatorname{sglT}$ was confirmed by RT-qPCR results (pvalue $<0.05$ ) with a repression fold of 6 at $3 \mathrm{~d}$ and 88 at $9 \mathrm{~d}$ post-inoculation (Additional file 3: Table S3).

The Wood-Werkman cycle is specific to certain propionic acid-producing bacteria. It plays a central role in propionic acid fermentation, the principal carbon metabolic pathway in dairy propionibacteria. This pathway provides major sources of reducing equivalents: NADPH required for biosynthesis reactions and NADH necessary for oxidative phosphorylation. Through this pathway, pyruvate is converted into propionate. Pyruvate is initially converted into succinate by the successive steps of the tricarboxylic cycle (TCA). At 3d post-inoculation, gene-set enrichment analysis identified the "Citrate Cycle" as one of the most down-regulated pathways (ko00020, fold change of 2.1, $p$ value $=2.7 \mathrm{e}-04)$. All the corresponding genes ( $m d h$, fumC and $s d h)$ were repressed, with fold changes of 1.9, 2.1 and 8.6, respectively, in stationary phase compared to exponential phase (see Additional file 2: Table S2). Succinate is then converted into succinyl-CoA, methyl malonyl CoA, propanoyl CoA and propionate by specific enzymes. Transcripts corresponding to the $12 \mathrm{~S}, 5 \mathrm{~S}$ and $1.3 \mathrm{~S}$ subunits of the well-studied methylmalonyl-CoA carboxyltransferase were repressed with fold changes of 2.3, 1.8 and 2.9 , respectively. RT-qPCR results confirmed the repression of $m m d a$, encoding the $12 \mathrm{~S}$ subunit with a fold change of 2. Down-regulation of the Wood-Werkman 
cycle is probably involved in maintaining the redox balance. Although glycolysis and the Wood Werkman cycle were down-regulated, all genes in the pentose phosphate pathway (except the rpiB3 gene, induced with a fold change of 2.9) were stably expressed between $1 \mathrm{~d}$ and $3 \mathrm{~d}$ post-inoculation.

\section{Changes in oxidative phosphorylation}

Several transcripts (nuoA,B,C,D,E,F,I,J,K,L,M,N genes) encoding the different chains of NADH-quinone oxidoreductase (responsible for the release of electrons and $\mathrm{H}$ + contained in the NADH molecule) involved in aerobic respiration were down-regulated at $3 \mathrm{~d}$ post-inoculation, with a fold change of between 3.8 and 6.3. The PFCIRM138_05930 gene encoding an iron-sulphur protein was also down-regulated, with a fold change of 6 in RNAseq analysis and 4.5 at $3 \mathrm{~d}$ and 5.5 at $9 \mathrm{~d}$ post- inoculation according to RT-qPCR results. Likewise, $s d h A, A 3$, $B, B 3, C 1$, and $C 2$, encoding the different subunits of succinate dehydrogenase, were down-regulated with fold changes of between 4.4 and 8.8 (for details, see Additional file 1: Table S1 and Additional file 2: S2). Repression of $s d h C 1$ was confirmed by RT-qPCR results with a repression with a fold of 9 (Additional file 3: Table S3). By contrast, both the $d m s C$ and $d m s B$ genes, encoding the anaerobic dimethyl sulphoxide reductase chains $C$ and $B$, were induced with fold changes of 13.7 and 4.7, respectively. The latter protein handles the final transfer of electrons to various sulphoxide and $\mathrm{N}$-oxide compounds. Anaerobiosis-inducible dimethyl sulphoxide reductases play a key role in bacterial adaptation to anaerobic conditions in bacteria and serve as terminal reductases using DMSO as a terminal electron acceptor [16]. Nitrate, sulphur or ferrous ions can act as electron acceptors. Accordingly, the gene encoding the permease protein of the nitrate $\mathrm{ABC}$ transporter $s s u C$ was induced with a fold change of 4.4, the gene citT2 encoding a sodium:sulphate symporter was induced with a fold change of 4.3, and the feuC and feuS genes encoding the ferrous $\mathrm{ABC}$ transporter were induced with fold-changes of 2.5 and 2.8. Some subunits of nitrate reductase, namely those encoded by narH and narJ, were induced by more than 22 -fold. RT-qPCR results confirmed the induction of narH with a lesser fold of 3.5. During growth, the headspace of the tube contained air and was therefore a source of $\mathrm{O}_{2}$. Although the culture was grown without agitation, the medium contained traces of $\mathrm{O}_{2}$, which were probably used as a terminal electron acceptor during the exponential growth phase. At 3d post-inoculation, the $\mathrm{CO}_{2}$ released by the bacteria likely saturated the headspace of the tube and the $P$. freudenreichii were in anoxic conditions. This might modify the redox balance due to the lower availability of reducing equivalents, and thus explain the down-regulation of oxidative phosphorylation. At the pathway level, geneset enrichment analysis (see Methods) showed that oxidative phosphorylation was indeed the most significantly down-regulated (ko00190, fold change of 4.4 and pval = 1.2e-12) of all of the pathways down-regulated during the study. A similar down-regulation had been observed when $P$. freudenreichii was placed in the colon of piglets under anoxic conditions [9]. To assess whether the oxydative repression is due to traces of $\mathrm{O}_{2}$ in the headspace or due to the metabolism at the entry into stationary phase, cultures growing in bioreactors under strictly controlled conditions can be considered.

The changes thus observed suggest profound metabolic reprogramming in response to starvation. Similarly, during our study, specific catabolic pathways were induced (see below).

\section{Cell wall}

The cell envelope of Gram positive bacteria such as P. freudenreichii comprises the inner cell (cytoplasmic) membrane and the cell wall of the bacterium composed of peptidoglycan and various associated compounds (proteins, polysaccharides, teichoic acids) that differ from one species to another. In P. freudenreichii, some strains are known to possess a surface exopolysaccharidic (EPS) layer composed of $(1 \rightarrow$ $3,1 \rightarrow 2)$ - $\beta$-D-glucan [17].

Peptidoglycan (PG) is essential to maintaining cell shape and also providing mechanical protection against osmotic pressure. It is also involved in cell division process. PG is a three-dimensional network made up of $\mathrm{N}$-acetylglucosamine (GlcNAc) and $\mathrm{N}$-acetylmuramic acid (MurNAc). The carboxyl groups of MurNAc are substituted by a short peptides, interconnecting the chains together. The biosynthesis of PG includes cytoplasmic steps mediated by MurA to $\mathrm{F}$, and thereafter the transfer through the membrane via the transferases MarY and MurG, and finally the binding of new material to cell wall. At entry into stationary phase, the PG biosynthesis pathway is significantly down-regulated. The genes encoding MurA and MurB that are involved in the formation of UDP-N-acetylmuramate were downregulated, with a fold changes of 1.8 for both. The murC, $D, E$, and $F$ genes encoding cytoplasmic enzymes responsible for the sequential adjunction of amino-acids to UDP-N-acetylmuramate, leading to the formation of UDP-MurNAc-pentapeptide, were also down-regulated (with fold changes of 2.3, 1.6, 1.2, and 2, respectively) as well as the gene $d d l A$ reponsible for the formation of the D-alanyl-D-alanine dipeptide is down regulated (fold changes of 2,9). Two proteins MraY and MurG ensure the transfer of the phospho-MurNAc-pentapeptide moity of the UDP-MurNAc-pentapeptide to the membrane acceptor and the addition of GlcNAc, leading to 
the formation of GlcNAc-MurNAc-pentapeptide on the lipid carrier. The mraY gene encoding UDP- MurNAcpentapeptide phosphotransferase was repressed with a fold change of 3.4, whereas expression of the $m u r G$ gene remained stable. Finally, the enzymes responsible of the late steps of the biosynthesis of the PG were also down regulated: $f s t I$ (fold change of 1.9) and $m r c / p o n A$ (fold change of 1.5). Taken together, our results showed a down-regulation of peptidoglycan synthesis, which agreed with the growth arrest and entry into dormancy observed for CIRM-BIA138.

The CIRM-BIA138 strain produces a surface $\beta$-Dglucan polysaccharide [18]. A single $g t f F$ gene is responsible for the synthesis of this polysaccharide. The gtfF gene is strongly induced in stationary growth phase compared to the exponential phase, with a fold change of 6.1, which might lead to an overproduction of surface $\beta$-D-glucan polysaccharide. The induction was confirmed with a fold change of 3.3 at $3 \mathrm{~d}$ but not at $9 \mathrm{~d}$ post-inoculation by RT-qPCR results. Such EPS production might protect the bacteria against the unfavourable conditions encountered in stationary phase and therefore prepare them for long-term survival, as has previously been shown in other food species such as Oenococcus oeni [18].

The cell wall of $P$. freudenreichii is also coated with proteins that are anchored via an SLH domain. SlpE, SlpF and SlpG are three of these proteins. Interestingly, during this study, the $\operatorname{slp} E$ gene was found to be strongly up-regulated (fold change of 12.9); whereas $\operatorname{slp} G$ and $s l p F$ were down-regulated (fold change of 2.8 and 2.2 respectively). According to RT-qPCR results, the induction of $s l p E$ is transient since it was confirmed at $3 \mathrm{~d}$ with a fold change of 5.5 but not at $9 \mathrm{~d}$ post-inoculation. As of yet, the physiological role of these proteins has not been elucidated, but these results suggest differing roles in long-term survival for SlpE and the other two proteins.

The bacterial membrane mostly comprises a proteinembedded phospholipid bilayer. In CIRM-BIA138, the fatty acid biosynthesis pathway was strongly repressed in stationary phase compare to exponential phase. The $f a b F$ and $f a b H$ genes encoding the enzyme charging the acetyl residue from acetyl-CoA to acyl-carrier protein (Acp) were repressed, with respective fold changes of 6.3 and 6.9. RT-qPCR results confirmed repression of $f a b F$ with a fold-change of 8.2 at $3 \mathrm{~d}$ and 6.6 at $9 \mathrm{~d}$ postinoculation. The $a c p$ gene was repressed, with a fold change of 5.9. In the same way, the $f a b D$ genes encoding the enzyme charging the malonyl residue from malonoyl-CoA to Acp was repressed, with a 3.7-fold change. Genes such as $f a b G$ or inhA, which are responsible for the further elongation of fatty acids, were repressed by 1.9 and 1.7, respectively. Bacteria can produce fatty acids anaerobically. Since most fatty acids in bacterial cells are used for membrane phospholipid synthesis, growth arrest at the entry into stationary phase at $3 \mathrm{~d}$ compared to $1 \mathrm{~d}$ post-inoculation (see CFU count, Fig. 1) might limit the need for fatty acids, and lead to the down-regulation we observed here.

\section{Diversification of nutrients}

At $3 \mathrm{~d}$ post-inoculation, glucose, lactose, and lactate were exhausted. $P$. freudenreichii therefore needed to recruit other catabolic pathways to produce NADH and NADPH reducing equivalents, ATP and precursor metabolites required for the survival. Inositol and arabinose pathways were induced. Gene-set enrichment analysis revealed that "Pentose and glucuronate interconversions" were the most markedly induced KEGG pathways (ko00040; fold change of 1.7, pval 0.003). In this large pathway, the degradation of arabinose appeared to be the only one to be induced.

\section{Arabinose}

Most $P$. freudenreichii strains can degrade L-arabinose, and the degradation pathway has previously been described [15]. L-arabinose enters the cell via a xylose/ribose/arabinose/galactoside $\mathrm{ABC}$ transporter encoded by $r b s B A$ that is not differentially expressed. L-arabinose is sequentially converted to L-ribulose, L- ribulose 5phosphate, and D-xylulose 5-phosphate by the action of the L-arabinose isomerase encoded by $\operatorname{araA}, \mathrm{L}$ ribulokinase encoded by $\operatorname{ara} B$ and ribulose-5- phosphate 4-epimerase encoded by $\operatorname{araD}$ and $\operatorname{araD1}$, which in our study were induced 2.2, 2.2, 1.1 and 2.9 fold, respectively. However, biochemical quantification failed to detect arabinose which is probably present at a concentration lower than the detection limit of $0.5 \mathrm{mM}$ (like glucose, lactose, fructose, mannose) in the medium.

\section{Inositol}

Inositol is a six-fold cyclohexane alcohol. Inositol is found in many foods (particularly in fruits) and is probably present in the yeast extract contained in YEL culture medium. Inositol is transported into the cell by a transporter encoded by iolT1, iolT2 and iolT3, which were found to be induced with respective fold changes of $11,3.2$ and 1.7, at the entry into stationary phase compared to exponential phase (Additional file 2: Table S2). The induction of iolT1 was induced 2.4 at $3 \mathrm{~d}$ and 58.3 at $9 \mathrm{~d}$ according to RT-qPCR results. In the cell, inositol is transformed into 2-keto-inositol by inositol dehydrogenase that is encoded by the iol, iolG2 genes, induced with fold changes of 5.5 and 2.1, respectively. 2keto-inositol is then transformed into 2,3-di-keto-4-deoxy inositol by 2-keto inositol dehydratase encoded by iolE3, which was found to be induced by a 2.2 fold change. 2,3-di-keto-4-deoxy inositol is then transformed 
into 2-deoxy-5-keto gluconic acid by the product of the iolB gene repressed with a fold change of 2.1. The iolC and iolD genes, whose products convert 2-deoxy-5-keto gluconic acid into malonic semialdehyde, were not differentially expressed. The induction of inositol degradation was not detected by GAGE, probably because the steps in this pathways are not fully described in the KEGG orthology map for $P$. freudenreichii species. The inositol degradation pathway had previously been annotated manually in all sequenced strains able to degrade inositol [15], and this revealed a high number of paralogous genes at different steps in the pathway (Fig. 3), suggesting that the pathway is essential for this species. During our study, we were able for the first time to demonstrate the expression and induction of the inositol degradation pathway in $P$. freudenreichii. Unfortunately, inositol was undetected in the culture medium (data not shown).

\section{Use of asparagine}

Biochemical analysis of the culture medium showed that asparagine was totally consumed between $1 \mathrm{~d}$ and $3 \mathrm{~d}$ post-inoculation (1.3 $\mathrm{mM}$ consumption, Fig. 4). The KEGG and Metacyc pathways report that in bacteria, asparagine is degraded into aspartate that is further transformed into fumarate or succinate. Despite asparagine exhaustion in the CIRM-BIA138 supernatant, the transcripts of asm $A$ and asmB enabling the transformation

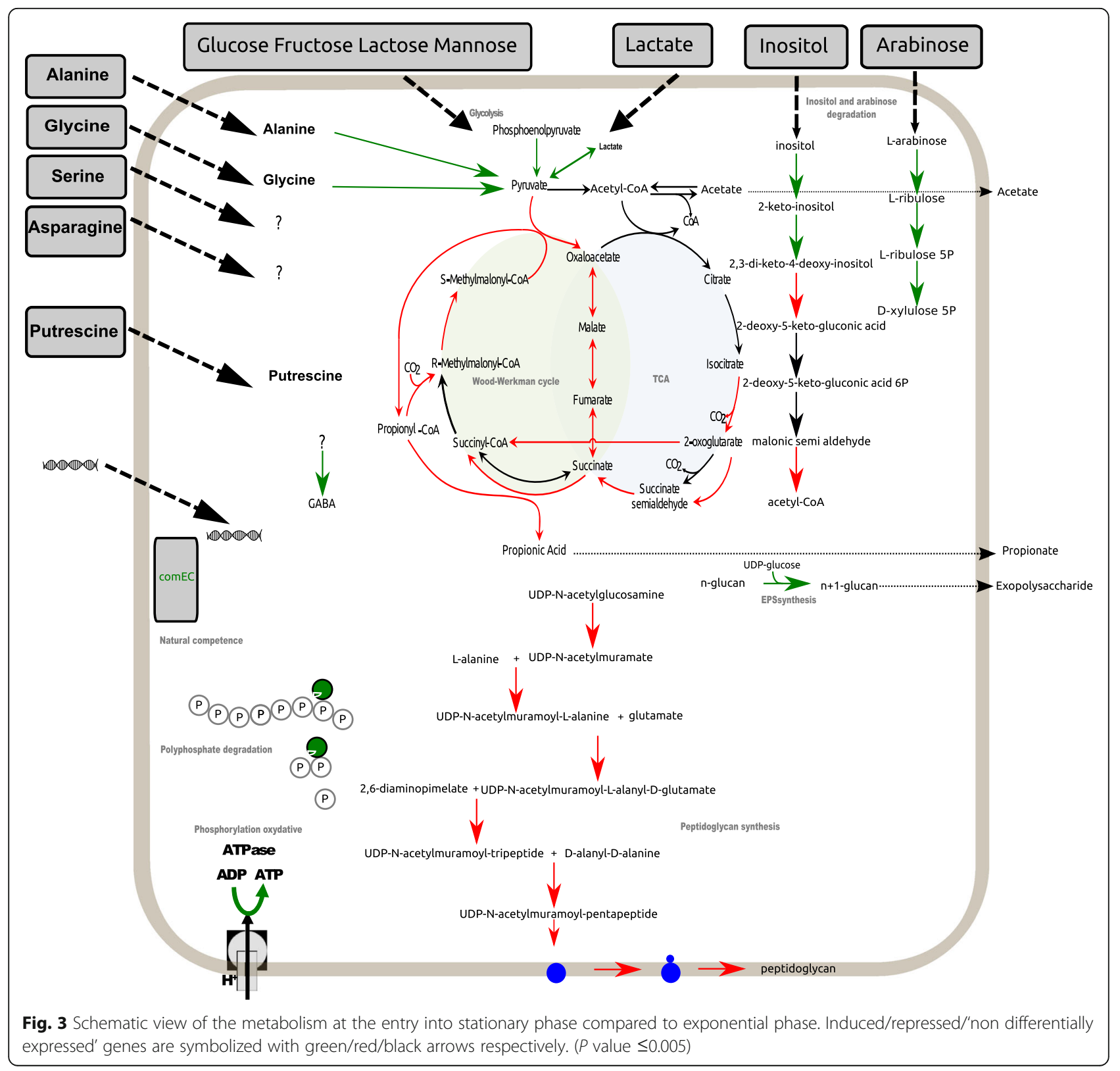




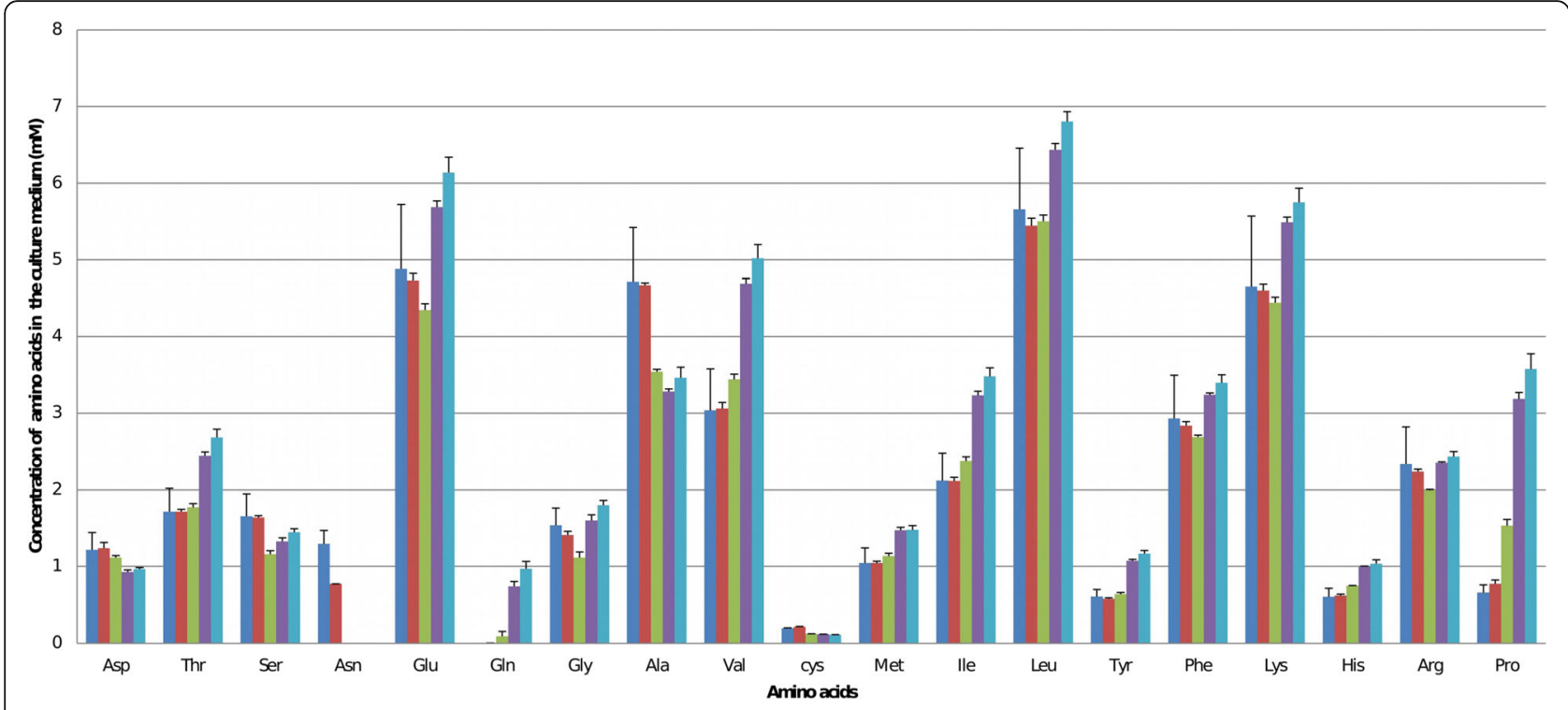

Fig. 4 Concentrations of free amino acids in the medium (mM) during growth and stationary phases. In dark blue at the time of inoculation, in red at $1 \mathrm{~d}$ post-inoculation, in green at $3 \mathrm{~d}$ post-inoculation, in purple at $9 \mathrm{~d}$ post-inoculation, in light blue at $11 \mathrm{~d}$ post-inoculation. Significant consumptions discussed in the text (serine, asparagine, glycine, alanine) correspond to the difference in concentration at $1 \mathrm{~d}$ and $3 \mathrm{~d}$ post-inoculation ( $t$-test, $P$ value adjusted $<0.05$ )

of asparagine into aspartate were both repressed at $3 \mathrm{~d}$ post-inoculation compared to $1 \mathrm{~d}$ post-inoculation, with fold changes of 2.1 and 1.5 , respectively. In $P$. freudenreichii, the fate of asparagine between $1 \mathrm{~d}$ and $3 \mathrm{~d}$ post-inoculation remains unknown [19]. The use of asparagine as an energy supply has previously been suggested [14]. Asparagine is described as being cometabolized along with aspartate and lactate in type strain P. freudenreichii CIRM-BIA1 [20]. However, the quantification of free aspartate did not support this idea in the P. freudenreichii CIRM-BIA138 strain. The concentration of free aspartate in the medium was not significantly different between $1 \mathrm{~d}$ and $3 \mathrm{~d}$ postinoculation ( $t$-test, $P$ value $>0.05)$. The majority (i.e., $70 \%$ of the $100 \mathrm{P}$. freudenreichii isolates previously tested) displayed very low levels of aspartate activity [21]. In CIRM-BIA138, the lack of aspartate consumption could be explained by the lack of the $d c u A$ gene enabling the transport of aspartate into the cell.

\section{Putrescine}

Putrescine is a deleterious biogenic amine that is often present in mature cheeses. In general, Swiss-type cheeses containing the $P$. freudenreichii species do not exhibit high levels of putrescine [22]. Whether this is due to the degradation of putrescine by $P$. freudenreichii remains to be demonstrated. The degradation pathway for putrescine has not yet been described in P. freudenreichii. During the present study, the PFCIRM138_100015 gene, putatively encoding a putrescine importer, was induced with a fold change of 3.7 at entry into stationary phase.
In $E$. coli, putrescine degradation is supported by the $\operatorname{gad} A$ and $\operatorname{gadB}$ gene products and involves steps that are shared with those of glutamate. The glutamate decarboxylase encoded by gadB was 5 -fold more induced at $3 \mathrm{~d}$ compared to $1 \mathrm{~d}$ post-inoculation. RT-qPCR results confirmed a strong and progressive induction of $\operatorname{gadB}$ with a fold change of 3 at $3 \mathrm{~d}$ and of 114 at $9 \mathrm{~d}$ postinoculation. The glutamate concentration did not differ statistically at $3 \mathrm{~d}$ and $1 \mathrm{~d}$ post-inoculation ( $t$-test, $P$ value $>0.05$ ), suggesting that degraded glutamate arose from the prior degradation of putrescine. This induction was also consistent with that observed in E. coli for the gadA and $\operatorname{gadB}$ genes during entry into stationary phase. It has been shown that glutamate decarboxylase activity increases the survival of Listeria monocytogenes, because intracellular glutamate is stored and converted into $\gamma$ aminobutyric acid (GABA), and extracellular glutamate is coupled to an antiporter in the gad system [23, 24]. The CIRM-BIA138 genome contains two genes encoding a GABA transferase: PFCIRM138_10030 (gabT), which was repressed with a fold change of 6.6, and PFCIRM138_04365, which was induced with a fold change of 10.6. However, neither GABA nor putrescine were detected in the medium despite a quantification limit of $25 \mu \mathrm{M}$ (data not shown). The induction of putrescine importer (PFCIRM138_100015) and $\operatorname{gadB}$ at d3 and $\mathrm{d} 9$ is not sufficient to know whether these both genes were involved in the metabolism of stationary phase and whether glutamate metabolism could be linked to an hypothetical putrescine degradation by $P$. freudenreichii. 


\section{Use of glycine}

The dosage of free glycine in the medium revealed a $0.42 \mathrm{mM}$ consumption between $1 \mathrm{~d}$ and $3 \mathrm{~d}$ postinoculation (Fig. 4). The dadA2 gene encoding glycine oxidase, which catalyses glycine oxidative deamination was induced at $3 \mathrm{~d}$ compared to $1 \mathrm{~d}$ post-inoculation, with a fold change of 13 according to RNAseq analysis but the induction was not statistically significant according to RT-qPCR result. This gene is the only one revealing a discrepency between RNAseq data and RT-qPCR analysis. However we can conclude to a maintain of $d a d A 2$ expression at $3 \mathrm{~d}$ and even at $9 \mathrm{~d}$ post-inoculation. During osmotic stress induced by a high $\mathrm{NaCl}$ concentration in a medium containing glycine betaine (also named trimethylglycine), it was found that Propionibacterium acidipropionici accumulates glycine betaine in order to balance osmolarity and enable adaptation [24]. Other studies have also shown that in $P$. freudenreichii, glycine and proline exert protective effects against high osmolarity throughout bacterial growth [19]. Internalization of glycine could be a way to cope with osmotic conditions encountered at the entry of stationnary phase.

\section{Use of alanine}

Alanine was the free amino acid that was most consumed (1.17 $\mathrm{mM}$ between $1 \mathrm{~d}$ and $3 \mathrm{~d}$ post-inoculation). This was in line with induction of the ald gene encoding an alanine dehydrogenase (2.7 fold change), which deaminates L-alanine into pyruvate. The induction of ald throughout growth has already been observed in stationary phase induced by low temperature in the absence of nutrient shortage [25]. We showed here that such ald induction also occurred in a context of nutrient shortage.

\section{The role of proline}

Biochemical analysis between 1d post-inoculation and $3 \mathrm{~d}$ post-inoculation an almost two-fold increase in proline was measured in the surpernatant $(0.87 \mathrm{mM}$ released) (Fig. 4). As no gene for proline synthesis was induced at $3 \mathrm{~d}$ post-inoculation, this suggests that proline was released due to the degradation of proteins and peptides in the medium. This was consistent with the action of a proline iminopeptidase (Pip) which cleaves aminoterminal proline residues from peptides and has previously been described in cheese [26].

\section{Chaperone and detox}

Protein chaperones protect other proteins against aggregation and denaturation. In P. freudenreichii, chaperones are strongly expressed in the case of acidic or bile salt stresses [27] or under cold conditions [25]. At 3d postinoculation, the three sequences $h s p 201, h s p 202$ and hsp20 3 encoding heat shock proteins were induced with fold changes of 6.7, 6.9 and 2.5, respectively. The copZ gene encoding a copper chaperone was induced with a fold change of 2.5. The $\operatorname{csp} B$ gene encoding a cold shock protein was induced with a 2.7 fold change. The number of chaperones induced seems low when compared to the large number of chaperone-encoding genes described in the literature for $P$. freudenreichii. The limited induction of chaperone genes might reflect the efficient adaptation of $P$. freudenreichii to nutritional shortage. Alternatively, and unlike osmotic or heat-shock stress, nutritional shortage may not induce protein misfolding or denaturation and thus not cause the expression of many chaperone genes.

\section{Competence}

In several species, natural competence enables the bacteria to cope with stresses or nutritional shortage. There are three prevailing hypotheses regarding the benefits of DNA uptake and recombination in bacteria (for a review, see [28, 29]): (i) DNA is used as a nutrient source; (ii) DNA is used to improve the efficiency of natural selection (by acquiring new genetic information); and (iii) DNA is used as a template to repair damaged chromosomal DNA. In the case of $P$. freudenreichii CIRM-BIA 138, a gene encoding DNA transfer protein (PFCIRM138_00630) was induced with a fold change of 14.7, and $d p r A$ encoding a DNA processing/uptake protein was induced with a fold change of 27.3 at $3 \mathrm{~d}$ post inoculation. Two contiguous genes encoding mobilization protein (PFCIRM138_07015, PFCIRM138_07020) were induced with fold changes of 49.4 and 10.8 respectively, one gene (PFCIRM138_07570) encoding a conjugative relaxase was induced with a 24 -fold change and lastly the comEC gene involved in competence was induced with a fold change of 17.4 at $3 \mathrm{~d}$ post-inoculation. PFCIRM138_07015 induction was confirmed by RTqPCR result with a fold change of 23.6 at $3 \mathrm{~d}$ and 26.7 at $9 \mathrm{~d}$ post-inoculation. The non coding RNA named 'Alil pseudoknot 'was induced with a fold change of 3 at the entry into stationary phase (Additional file 1: Table S1). It is known to stimulate the expression of transposase, an enzyme required for transposition. $P$. freudenreichii is known to have evolved more by recombination than by mutations [30] and possesses a high copy number of insertion sequences and integrase genes in its genome [7]. Here, several genes involved in natural competence were found to be induced under the conditions applied. However, neither natural competence nor conjugation has been described in this species to date. Cultures of CIRM-BIA138 in presence of high concentration of insertional plasmid (data not shown) failed to illustrate natural competence. 


\section{Utilization of pyrophosphate}

$P$. freudenreichii can accumulate inorganic polyphosphate (polyP) as an energy reserve whereas most bacteria utilize ATP [7]. The ability to use polyphosphate as an energy reserve has been shown to be specific to bacteria adapted to difficult environments. The CIRM-BIA138 genome possesses 20 genes encoding enzymes which use polyphosphate or pyrophosphate. At the start of the stationary phase during our study (at $3 \mathrm{~d}$ post-inoculation), three phosphorylases were induced when compared to exponential growth phase at $1 \mathrm{~d}$ post-inoculation: (i) $p p \times 5$, encoding an exopolyphosphatase with a 19.8 fold change, (ii) ppa encoding an inorganic pyrophosphatase with a 1.6 fold change, and (iii) PFCIRM138_07685 encoding a NUDIX hydrolase with a 3 fold change. The phoH gene, encoding a phosphate-starvation inducible protein, was induced with a 2.5 fold change. In Corynebacterium glutamicum, another Actinobacterium that is phylogenetically close to $P$. freudenreichii, previous microarray results showed an induction of the phoH gene with a fold change ranging from 1.1 to 6.8 under Pi-limiting conditions compared to non-limiting conditions [31]. In many species, strains with a mutation in the gene involved in polyphosphate ( $p p k)$ synthesis are unable to survive during stationary phase [32]. Taken together, these results suggested a possible limitation of the availability of soluble phosphate causing $P$. freudenreichii to use polyphosphates stored in its cytoplasm during stationary phase to cover its phosphate requirements. Since the phosphate starvation response is critical for the persistence of Mycobacterium tuberculosis (another Actinobacterium) in the lung [33], the role of phosphate starvation in the entry of $P$. freudenreichii into dormancy needs to be further explored, e.g., by quantifying extracellular phosphate and intracellular polyphosphate and by directed mutagenesis on key enzymes in the polyphosphate synthesis pathway.

\section{Conclusions}

At entry into stationary phase, $P$. freudenreichii adapts its metabolism to nutritional shortage and slows down its metabolism. Genes involved in oxidative phosphorylation and fermentation (via the WoodWerkman cycle) are repressed, in line with the lack of lactate in the medium, enabling the entry into dormancy. By contrast, $P$. freudenreichii diversifies its source of nutrients and appears to utilize amino acids which differ from those used during the exponential phase according to RNAseq analysis, RT-qPCR and amino acids quantification. To meet its energy needs $P$. freudenreichii probably utilizes polyphosphate, because several phosphatases were found to be induced during this study. These results therefore provide an analysis of $P$. freudenreichii adaptation during entry into stationary phase by means of comprehensive gene expression analysis using RNA-Seq combined with targeted biochemical quantifications. They shed light on important molecular mechanisms that might be involved in the long-term survival of $P$. freudenreichii, and open avenues for further investigation on its survival strategies.

\section{Methods}

\section{Bacterial strains}

P. freudenreichii CIRM-BIA138 (alias ITG P9) strain was used during this work. The strain was supplied by the International Centre for Microbial Resources-Bacteria of Food Interest (Centre International de Ressources Microbiennes-Bactéries d'Intérêt Alimentaire; INRA, Rennes).

\section{Conditions for bacterial growth}

The strain was cultured in YEL medium $(\mathrm{pH}=7.0)$ [34] with no agitation at $30{ }^{\circ} \mathrm{C}$ for 11 days. The strain was grown in a different assay tube for each manipulation, thus preventing any interference of oxygen in the environment and maintaining the strain under microaerophilic conditions. At T0, the medium was inoculated at $10^{7} \mathrm{CFU} / \mathrm{mL}$ and the inoculated culture was then split into 5 tubes of $10 \mathrm{ml}$ at $\mathrm{T} 0$.

The growth kinetics were followed using Optical Density measurements with a Model DU 640 spectrophotometer (Beckman Coulter, Fullerton, California, USA) at $650 \mathrm{~nm}\left(\mathrm{OD}_{650}\right)$, and the $\mathrm{CFU}(\mathrm{CFU} / \mathrm{mL})$ were counted using the micromethod described previously [35]. P. freudenreichii enumerations were carried out on YEL agar at $30{ }^{\circ} \mathrm{C}$ under microaerophilic conditions, until the visualization of colonies (6 days). Two technical replicates and two biological replicates were performed for growth curves analysis, and three biological replicates were performed for RNA-seq and biochemical analysis. Aliquots of the culture were sampled for RNA extraction, $\mathrm{pH}$ measurements and biochemical analysis (see above) on the day of inoculation and at $1 \mathrm{~d}, 3 \mathrm{~d}$ and 9d post-inoculation.

\section{RNA extraction and quality control}

$1 \mathrm{ml}$ of each culture was mixed with 2 volumes of RnaProtect (Qiagen, Hilden, Germany), left for $5 \mathrm{~min}$ at room temperature and then centrifuged $(8,000 \mathrm{~g}, 10 \mathrm{~min}$ at room temperature). The supernatant was removed and the pellet stored at $-80{ }^{\circ} \mathrm{C}$ until total RNA was extracted. The pellets were thawed on ice, suspended in $200 \mu \mathrm{L}$ lysis buffer $(50 \mathrm{mM}$ Tris-HCl, $1 \mathrm{mM}$ EDTA; $\mathrm{pH}$ 8.0) containing $20 \mathrm{mg} / \mathrm{mL}$ lysozyme (MP Biomedicals, Illkirch, France) and $50 \mathrm{U} / \mathrm{mL}$ mutanolysin (Sigma, Saint Quentin Fallavier, France), and incubated for $15 \mathrm{~min}$ at $24{ }^{\circ} \mathrm{C}$. The suspensions were then transferred to two millilitre tubes containing $50 \mathrm{mg}$ zirconium beads 
(diameter: $0.1 \mathrm{~mm}$; BioSpec Products, Bartlesville, OK) and $100 \mu \mathrm{L}$ SDS (10\%). The tubes were shaken twice for $90 \mathrm{~s}$ at $30 \mathrm{~Hz}$ with a bead beater (MM301; Retsch, Haan, Germany), being chilled on ice for $2 \mathrm{~min}$. between the shaking steps. RNA extraction was then performed using an RNeasy minikit (Qiagen) and the Qiacube extraction robot (Qiagen), according to the manufacturer's instructions. RNA were suspended in $50 \mu \mathrm{L}$ RNase-free water and treated with DNase (DNA-free; Ambion, Cambridgeshire, United Kingdom) according to the supplier's instructions, and then stored at $-80{ }^{\circ} \mathrm{C}$ until use. RNA was then quantified and the contamination of RNA by proteins was assessed spectrophotometrically using a NanoDrop ND-1000 spectrophotometer (NanoDrop Technologies, Inc., Rockland, DE, USA). RNA quality was evaluated using an Agilent 2100 Bioanalyzer (Agilent Technologies, Santa Clara, CA, USA). All the RNA samples from spent medium had a RIN value higher than 7.5, indicative of good rRNA integrity. RNA was then depleted using RiboZero Magnetic kit for Gram positive bacteria (Epicentre, Madison,WI, USA) according to the manufacturer's instructions. Depleted RNA quality was evaluated using an Agilent 2100 Bioanalyzer (Agilent Technologies, Santa Clara, CA, USA) and nanoarrays for prokaryotes.

\section{Sequencing of mRNA}

The cDNA libraries were prepared from the depleted RNA for each of the three repetitions of the exponential phase (1d post-inoculation), stationary phase (3d postinoculation) and long-term survival (9d postinoculation) and then prepared for sequencing using the Illumina TruSeq Stranded mRNA LT Sample Preparation kit. The nine oriented RNA-seq libraries were prepared using the TruSeq Stranded mRNA Sample Preparation kit, according to the manufacturer's instructions. Qualitative and quantitative library validations were performed on a DNA 1000 Agilent chip as well as using quantitative PCR with SYBR Green (Applied Biosystem 7500). The libraries were sequenced on an Illumina HiSeq 2000 as 50 bp reads using the Sequence By Synthesis technique at the Montpellier GenomiX facility. Image analyses and base calling were performed using the Illumina HiSeq Control Software and Real-Time Analysis component. Demultiplexing was performed using Illumina's sequencing analysis software (CASAVA 1.8.2). Data quality was assessed using FastQC from the Babraham Institute and the Illumina software SAV (Sequencing Analysis Viewer). The concentration in the samples corresponding to long-term survival (9d postinoculation) were too low for sequencing and revealed contamination with genomic DNA, so they were not further analysed.

\section{RNA-seq analysis}

Sequences were mapped with Bowtie [36]. To detect non-coding RNA, mapped sequence files where pooled by phase (exponential or stationary). Then, each file was submitted to Detr'Prok [37] to detect positions of small RNA, antisens RNA and 5' Untranslated regions. Bedtools [38] is used to extract corresponding sequences. Sequences where submitted to Rfam [39] to eliminate non characterized sequences. Finaly, non coding RNA validated by Rfam and CDS were counted with htseqcount [40] using the ABIMS Roscoff platform. A list of differentially expressed genes was generated using an $R$ software package: SARtools [41], embedded Deseq2 [42] and EdgeR [43] (modified $t$-test adjusted, Pvalues $<0.05$ ). A comparison of the results obtained with either Deseq2 or EdgeR produced a more exhaustive list using EdgeR. Most of the differentially expressed genes from Deseq2 were present in the EdgeR results. For this reason, only the results obtained using EdgeR are discussed below.

The protein sequences of the strain were subjected to a search against the Kyoto Encyclopedia of Genes and Genomes Pathway database (KEGG) using GhostKOALA (http://www.kegg.jp/ghostkoala/) to retrieve KEGG orthology (KO) identifiers. 1143 out of 2304 genes were annotated automatically. Differentially expression data were associated with these $\mathrm{KO}$ identifiers and underwent gene set enrichment analysis on KEGG orthology pathways using the GAGE package [44] of $R$ software to highlight pathways that were significantly differentially expressed (pval $<0.1$ ).

\section{RT-qPCR validation}

cstA, eno1 and $s d a A$ were used as housekeeping genes. Relative quantification relates the PCR signal of the target transcript at $3 \mathrm{~d}$ and $9 \mathrm{~d}$ post-inoculation compared to that of the inoculation time used as control. Before RTqPCR, a supplementary DNAse treatment was applied to total RNA from 0, 3d and 9d post-inoculation samples. cDNA were obtained from a retrotranscription step using iScript cDNA synthesis kit (Bio-Rad, Marne la Coquette, France). cDNAs were amplified as follows: each PCR mixture included $5 \mu \mathrm{l}$ of $1 / 50$ diluted cDNA, $3 \mu \mathrm{l}$ of $200 \mathrm{nM}$ of primers, $8 \mu \mathrm{l}$ of IQ Sybr Green supermix (Bio-Rad, Marne la Coquette, France). Amplifications were carried out on a CFX96 Real Time System (Bio-Rad) for $5 \mathrm{~min}$ at $95{ }^{\circ} \mathrm{C}$ and 40 cycles of 2 steps consisting of 15 seconds at $95^{\circ} \mathrm{C}$ and 30 seconds at $60{ }^{\circ} \mathrm{C}$. The relative quantification of the mRNA levels of the target genes was determined using CFX Manager (Bio-Rad, Marne la Coquette, France). The amount of target was normalized to cstA, eno1 and sdaA genes because they were revealed as stably expressed according to the software: Delta $\mathrm{C}_{\mathrm{q}}=\mathrm{C}_{\mathrm{q}}$ (target gene) $-\mathrm{C}_{\mathrm{q}}$ (housekeeping 
gene), where $\mathrm{C}_{\mathrm{q}}$ represents the cycle number required to reach a defined threshold target abundance.

\section{Metabolome analysis}

The samples used for this study had previously been frozen at $-20{ }^{\circ} \mathrm{C}$. These analyses were performed on the following samples: (i) YEL culture medium, (ii) exponential (1d post-inoculation), (iii) stationary (3d postinoculation), (iv) late stationary (9d post-inoculation) and (v) long-term survival (11d post-inoculation), with three biological replicates of each sample. The YEL culture medium was used as a control.

- Amino acid assays proteins and peptides. in the samples were precipitated by adding solid sulphosalicylic acid to $5 \%$ (w/vol), holding at $4{ }^{\circ} \mathrm{C}$ for $1 \mathrm{~h}$, and centrifuged (5,000 g, $15 \mathrm{~min})$. The supernatant was filtered through a $0.45 \mu \mathrm{m}$ pore size filter and diluted with a $0.2 \mathrm{~mol} / \mathrm{L}$ lithium citrate buffer (pH 2.2) before injection. Amino acid analyses were then carried out using cation exchange chromatography on a Biochrom 30 AA analyser (Biochrom Ltd, Cambridge, UK) according to the method described by Moore et al. (1958) with lithium citrate buffers as eluents and the ninhydrin post-column reaction system. Data were recovered using the control software Biosys and chromatographic data were processed with EZChrom Elite.

- Quantification of lactate, pyruvate, acetate, citrate and propionate. lactic, propionic, acetic, succinic and pyruvic acids were quantified in culture supernatants using an HPLC Aminex A-6 ion exchange column (Bio-Rad, Hercules, CA, USA) at $60{ }^{\circ} \mathrm{C}$ with $0.005 \mathrm{M} \mathrm{H} 2 \mathrm{SO} 4$ at an eluent flow rate of $0.4 \mathrm{ml} \mathrm{min}-1$. Acids were detected by UV $(210 \mathrm{~nm})$ and/or refractometry (RI2031 plus, Jasco).

- Quantification of arabinose and inositol. Concentrations were measured in culture supernatants by high performance liquid chromatography (Agilent Technologies 1200 Series, Waldbronn, Germany) using a $\mathrm{HPX} 87 \mathrm{H}^{+}$Biorad column and the following conditions: a temperature of $48{ }^{\circ} \mathrm{C}$, eluent $\mathrm{H} 2 \mathrm{SO} 4(5 \mathrm{mM})$ at a flow rate of $0.5 \mathrm{~mL} / \mathrm{min}$, and dual detection (refractometer and UV).

- Quantification of glucose, mannose, fructose and lactose. The supernatant of culture medium was deproteinized using Vivaspin $10 \mathrm{kDa}$ filters. Glucose, mannose, fructose, and lactose were separated on a CarboPacMA1 $(4 \times 250 \mathrm{~mm})$ analytical column (preceded by a corresponding guard column $50 \times$ $4 \mathrm{~mm}$ ) with $16 \mathrm{mM} \mathrm{NaOH}$ as the eluent and a flow rate of $1 \mathrm{~mL} / \mathrm{min}$ using an ICS-3000 chromatography/detector module (Dionex) and a range of 1 $\mu \mathrm{C}$. A solution containing each of the four sugars (glucose, mannose, fructose and lactose) (Sigma-Aldrich) at 2, 5,10, 20 and $40 \mathrm{mg} / \mathrm{L}$ (linearity range) was used as a standard. Detection and quantification were performed using amperometry and expressed in $\mu \mathrm{C}$.

\section{Additional files}

Additional file 1: Table S1. List of repressed genes in stationary phase (3d post-inoculation) compared to exponential phase (1d post-inoculation) ( $P$ value adjusted $\leq 0.05)$. (XLSX $96 \mathrm{~kb}$ )

Additional file 2: Table S2. List of genes induced in the stationary phase (3d post-inoculation) compared to the exponential phase (1d postinoculation) ( $P$ value adjusted $\leq 0.05)$. (XLSX $98 \mathrm{~kb}$ )

Additional file 3: Table S3. RT-qPCR results for validation of RNAseq results. (XLSX 9 kb)

\section{Abbreviations}

CFU: Colony forming unit; EPS: Exopolysaccharide; GlcNAc: Nacetylglucosamine; LTS: Long-term survival; MurNAc: N-acetylmuramic acid; PG: Peptidoglycan; RNAseq: Ribonucleic acid sequencing; RTqPCR: Retrotranscription quantitative polymerase chain reaction; UTR: Untranslated region; YEL: Yeast extract lactate

\section{Acknowledgements}

We are very grateful to the ABIMS platform (CNRS Roscoff, France) for providing scientific computing environment using Galaxy, and assistance with the RNA-seq analysis. Our thanks also go to Vicky Hawken for her English revision of the paper.

\section{Funding}

This work was supported by the CAPES-COFECUB French-Brazilian Cooperation Programme. We also wish to thank the Institut National de la Recherche Agronomique (INRA, UMR 1253, STLO, Rennes, France) for its financial and practical support.

\section{Availability of data and materials}

The dataset supporting the conclusions of this article is available in the GEO repository, [GSE75553 in http://www.ncbi.nlm.nih.gov/geo/query/ acc.cgi?acc=GSE75553].

\section{Authors' contributions}

FA and HF wrote the paper. SMD and AT participated in its compilation. GH, $E B$, and MBM quantified the amino acids, sugars and organic acids. HP compiled the library and performed the sequencing. MR undertook the demultiplexing and quality control of the reads obtained. MNM cared for the strain. SP performed quantitative PCR. AN performed the statistical analyses and ncRNA detection and quantification. HF mapped the RNA-Seq data and reconstructed the pathways. AM, VA and YLL supervised the work. All authors read and approved the final manuscript.

\section{Competing interests}

The authors declare that they have no competing interests.

\section{Consent for publication}

Not applicable.

Ethical approval and consent to participate

Not applicable.

\section{Author details}

'Department of General Biology, Federal University of Minas Gerais, Belo Horizonte, Minas Gerais, Brazil. ${ }^{2}$ INRA, UMR 1253, Science et Technologie du Lait et de I' Fuf, 35000 Rennes, France. ${ }^{3}$ AGROCAMPUS OUEST, UMR1253, UMR Science et Technologie du Lait et de I'CEuf, 35000 Rennes, France. ${ }^{4}$ UMS BioCampus- MGX Montpellier GenomiX, Institut de Génomique 
Fonctionelle, 141, rue de la Cardonnille, 34094 Montpellier Cedex 05, France. ${ }^{5}$ LISBP, Université de Toulouse, CNRS, INRA, INSA, 135 avenue de Rangueil, Toulouse 31077, France.

\section{Received: 14 July 2016 Accepted: 2 December 2016} Published online: 08 December 2016

\section{References}

1. Isawa K, Hojo K, Yoda N, Kamiyama T, Makino S, Saito M, et al. Isolation and identification of a new bifidogenic growth stimulator produced by Propionibacterium freudenreichii ET-3. Biosci Biotechnol Biochem. 2002;66: $679-81$

2. Jan G, Rouault A, Maubois JL. Acid stress susceptibility and acid adaptation of Propionibacterium freudenreichii subsp shermanii. Lait. 2000;80:325-36.

3. Okada Y, Tsuzuki Y, Miyazaki J, Matsuzaki K, Hokari R, Komoto S, et al. Propionibacterium freudenreichii component 1.4-dihydroxy-2-naphthoic acid (DHNA) attenuates dextran sodium sulphate induced colitis by modulation of bacterial flora and lymphocyte homing. Gut. 2006;55: 681-8.

4. Le Maréchal C, Peton V, Plé C, Vroland C, Jardin J, Briard-Bion V, et al. Surface proteins of Propionibacterium freudenreichii are involved in its antiinflammatory properties. J Proteomics. 2015;113:447-61.

5. Benz M, Schink B, Brune A. Humic acid reduction by Propionibacterium freudenreichii and other fermenting bacteria. Appl Environ Microbiol. 1998; 64:4507-12.

6. de Freitas R, Madec M-N, Chuat V, Maillard M-B, Mukdsi MCA, Falentin $\mathrm{H}$, et al. New insights about phenotypic heterogeneity within Propionibacterium freudenreichii argue against its division into subspecies. Dairy Sci Technol. 2015:95:465-77.

7. Falentin H, Deutsch S-M, Jan G, Loux V, Thierry A, Parayre S, et al. The complete genome of propionibacterium freudenreichii CIRM-BIA1T, a hardy actinobacterium with food and probiotic applications. PLOS ONE. 2010;5: e11748. Ahmed N.

8. Dalmasso M, Aubert J, Even S, Falentin H, Maillard M-B, Parayre S, et al. Accumulation of Intracellular glycogen and trehalose by Propionibacterium freudenreichii under conditions mimicking cheese ripening in the cold. Appl Environ Microbiol. 2012;78:6357-64.

9. Saraoui T, Parayre S, Guernec G, Loux V, Montfort J, Le Cam A, et al. A unique in vivo experimental approach reveals metabolic adaptation of the probiotic Propionibacterium freudenreichii to the colon environment. BMC Genomics. 2013;14:911.

10. Leverrier P, Vissers JP, Rouault A, Boyaval P, Jan G. Mass spectrometry proteomic analysis of stress adaptation reveals both common and distinct response pathways in Propionibacterium freudenreichii. Arch Microbiol. 2004; 181:215-30.

11. Leverrier $P$, Dimova D, Pichereau V, Auffray $Y$, Boyaval $P$, Jan G. Susceptibility and adaptive response to bile salts in Propionibacterium freudenreichii: physiological and proteomic analysis. Appl Environ Microbiol. 2003;69:3809-18.

12. Leverrier $P$, Fremont $Y$, Rouault $A$, Boyaval $P$, Jan $G$. In vitro tolerance to digestive stresses of propionibacteria: influence of food matrices. Food Microbiol. 2005;22:11-8.

13. Aburjaile FF, Madec M-N, Parayre S, Miyoshi A, Azevedo V, Le Loir $Y$, et al. The long-term survival of Propionibacterium freudenreichii in a context of nutrient shortage. J Appl Microbiol. 2015;120:432-40.

14. Piveteau P. Metabolism of lactate and sugars by dairy propionibacteria: a review. Lait. 1999;79:23-41.

15. Loux V, Mariadassou M, Almeida S, Chiapello H, Hammani A, Buratti J, et al. Mutations and genomic islands can explain the strain dependency of sugar utilization in 21 strains of Propionibacterium freudenreichii. BMC Genomics. 2015;16:296.

16. Jacobsen I, Hennig-Pauka I, Baltes N, Trost M, Gerlach G-F. Enzymes Involved in anaerobic respiration appear to play a role in Actinobacillus pleuropneumoniae Virulence. Infect Immun. 2004:73:226-34.

17. Deutsch SM, Bivic PL, Herve C, Madec MN, Lapointe G, Jan G, et al. Correlation of the capsular phenotype in Propionibacterium freudenreichii with the level of expression of gtf, a unique polysaccharide synthaseencoding gene. Appl Environ Microbiol. 2010;76:2740-6.

18. Dimopoulou M, Vuillemin M, Campbell-Sills H, Lucas PM, Ballestra P, MiotSertier C, et al. Exopolysaccharide (EPS) synthesis by oenococcus oeni: from genes to phenotypes. PLoS ONE. 2014;9:e98898.
19. Gagnaire V, Jardin J, Rabah H, Briard-Bion V, Jan G. Emmental cheese environment enhances Propionibacterium freudenreichii stress tolerance. Plos One. 2015;10:e0135780.

20. Crow VL. Metabolism of aspartate by Propionibacterium-Freudenreichii Subsp Shermanii - effect on lactate fermentation. Appl Environ Microbiol. 1986;52:359-65.

21. Blasco L, Kahala M, Tupasela T, Joutsjoki V. Determination of aspartase activity in dairy Propionibacterium strains. Fems Microbiol Lett. 2011;321:10-3.

22. EFSA Panel on Biological Hazards (BIOHAZ). Scientific opinion on scientific opinion on risk based control of biogenic amine formation in fermented foods. EFSA J. 2011:9:2393.

23. Cotter PD, Gahan CGM, Hill C. A glutamate decarboxylase system protects Listeria monocytogenes in gastric fluid. Mol Microbiol. 2001:40:465-75.

24. Kylma AK, Jokela J, Leisola M. Effect of glycine betaine on osmoadaptation of Propionibacterium acidipropionici cultivated in elevated osmolarities. Appl Microbiol Biotechnol. 2000;54:705-10.

25. Dalmasso M, Aubert J, Briard-Bion V, Chuat V, Deutsch S-M, Even S, et al. A temporal -omic study of Propionibacterium freudenreichii CIRM-BIA1T Adaptation strategies in conditions mimicking cheese ripening in the cold. PLOS ONE. 2012:7:e29083. Gilbert JA.

26. Fox PF, O'Connor TP, McSweeney PLH. Cheese: physical, biochemical, and nutritional aspects. Adv Food Nutr Res. 1996:39:163-328.

27. Jan $G$, Leverrier P, Pichereau V, Boyaval P. Changes in protein synthesis and morphology during acid adaptation of Propionibacterium freudenreichii. Appl Environ Microbiol. 2001;67:2029-36.

28. Claverys J-P, Prudhomme M, Martin B. Induction of competence regulons as a general response to stress in gram-positive bacteria. Annu Rev Microbiol. 2006:60:451-75

29. Vos M. Why do bacteria engage in homologous recombination? Trends Microbiol. 2009;17:226-32

30. Dalmasso M, Nicolas $\mathrm{P}$, Falentin $\mathrm{H}$, Valence $\mathrm{F}$, Tanskanen J, Jatila $\mathrm{H}$, et al. Multilocus sequence typing of Propionibacterium freudenreichii. Int J Food Microbiol. 2011:145:113-20.

31. Ishige T, Krause M, Bott M, Wendisch VF, Sahm H. The phosphate starvation stimulon of Corynebacterium glutamicum determined by DNA microarray analyses. J Bacteriol. 2003;185:4519-29.

32. Grillo-Puertas M, Villegas JM, Rintoul MR, Rapisarda VA. Polyphosphate Degradation in Stationary Phase Triggers Biofilm Formation via LuxS Quorum Sensing System in Escherichia coli. PLOS ONE. 2012;7(11):e50368.

33. Rifat D, Bishai WR, Karakousis PC. Phosphate depletion: a novel trigger for Mycobacterium tuberculosis persistence. J Infect Dis. 2009;200: $1126-35$

34. Malik AC, Reinbold GW, Vedamuthu ER. Evaluation of the taxonomy of the Propionibacterium. Canandian J Microbiol. 1968;1185-91.

35. Baron F, Cochet MF, Ablain W, Grosset N, Madec MN, Gonnet F, et al. Rapid and cost-effective method for microorganism enumeration based on miniaturization of the conventional plate-counting technique. Lait. 2006;86:251-7.

36. Langmead B, Trapnell C, Pop M, Salzberg SL. Ultrafast and memory-efficient alignment of short DNA sequences to the human genome. Genome Biol. 2009:10:R25

37. Toffano-Nioche C, Luo Y, Kuchly C, Wallon C, Steinbach D, Zytnicki M, et al. Detection of non-coding RNA in bacteria and archaea using the DETR'PROK galaxy pipeline. Methods. 2013;63:60-5.

38. Quinlan AR, Hall IM. BEDTools: a flexible suite of utilities for comparing genomic features. Bioinformatics. 2010;26:841-2

39. Nawrocki EP, Burge SW, Bateman A, Daub J, Eberhardt RY, Eddy SR, et al. Rfam 12.0: updates to the RNA families database. Nucleic Acids Res. 2015;43:D130-7

40. Anders S, Pyl PT, Huber W. HTSeq-a python framework to work with highthroughput sequencing data. Bioinformatics. 2015;31:166-9.

41. Varet H, Brillet-Guéguen L, Coppée J-Y, Dillies M-A. SARTools: a DESeq2- and edgeR-based R pipeline for comprehensive differential analysis of RNA-Seq data. PLoS ONE. 2016;11:e0157022

42. Love Ml, Huber W, Anders S. Moderated estimation of fold change and dispersion for RNA-seq data with DESeq2. Genome Biol. 2014;15:550.

43. Robinson MD, McCarthy DJ, Smyth GK. edgeR: a Bioconductor package for differential expression analysis of digital gene expression data. Bioinformatics. 2010:26:139-40.

44. Luo W, Friedman MS, Shedden K, Hankenson KD, Woolf PJ. GAGE: generally applicable gene set enrichment for pathway analysis. BMC Bioinformatics. 2009;10:161. 